\title{
Cumulative Troponin T Release after Acute Myocardial Infarction. Influence of Reperfusion
}

\author{
Johannes A. Kragten ${ }^{1}$, Wim Th. Hermens ${ }^{2}$ and Marja P. van Dieijen-Visser ${ }^{3}$ \\ 1 Department of Cardiology, Hospital DeWever and Gregorius, Heerlen, The Netherlands \\ 2 Cardiovascular Research Institute Maastricht, University of Maastricht, Maastricht, The Netherlands \\ ${ }^{3}$ Department of Clinical Chemistry, Academic Hospital, Maastricht, The Netherlands
}

Summary: For troponin $\mathrm{T}$ a characteristic biphasic change in the plasma time-concentration curve has been described, especially in patients with early reperfusion after thrombolytic therapy. As troponin $T$ is bound to myofibrillar structures, treatment strategy or treatment outcome could influence the cumulative plasma release of this protein in a different way compared to the cumulative release of free cytoplasmic cardiac enzymes.

The present study is the first study comparing the total quantity of troponin $\mathrm{T}$ released by the heart during the first 168 hours after acute myocardial infarction, both in patients treated with thrombolytic therapy $(n=16)$ and in patients not treated with thrombolytic therapy $(n=7)$. On the basis of clinical symptoms and coronary arteriogram within 24 hours, the patients treated with thrombolytic therapy were divided into two groups, reperfused $(n=9)$ and non-reperfused $(n=7)$. In the patients not treated with thrombolytic therapy, absence of spontaneous early reperfusion was judged only from clinical symptoms.

Cumulative troponin $\mathrm{T}$ release into plasma was compared to the cumulative release of the cytoplasmic cardiac enzymes creatine kinase (EC 2.7.3.2) and hydroxybutyrate dehydrogenase (EC 1.1.1.27). Cumulative release, i.e., infarct size, was calculated using a two-compartment model for circulating proteins. Mean tissue contents, per gram wet weight, of $156 \mathrm{U} / \mathrm{g}$ for hydroxybutyrate dehydrogenase, $2.163 \mathrm{U} / \mathrm{g}$ for creatine kinase and $234 \mu \mathrm{g} / \mathrm{g}$ for troponin $\mathrm{T}$, were used to express infarct size in gram-equivalents of healthy myocardium per litre plasma (g-eq/l).

Release rates were represented by the ratio of cumulative quantities released in 10 hours and 72 hours for creatine kinase and hydroxybutyrate dehydrogenase and in 10 hours and 168 hours for troponin $\mathrm{T}$.

\section{Conclusions}

- Plasma time-concentration curves and release rates of troponin $T$ in patients treated with thrombolytic therapy showing reperfusion differ significantly from those of patients not treated with thrombolytic therapy, showing no reperfusion.

- Creatine kinase and hydroxybutyrate dehydrogenase release is completed within $72-100$ hours in all patients, whereas troponin $\mathrm{T}$ release still continues after 168 hours.

- Cumulative troponin $\mathrm{T}$ release at 168 hours is only a fraction (around 8\%) of cumulative cytoplasmic enzyme release and the percentage released is not influenced by the treatment strategy or outcome, i. e., vessel patency.

- Although troponin $\mathrm{T}$ release is only a fraction of the cumulative enzyme release (infarct size) there is a highly significant correlation between both, independent of the treatment strategy or treatment outcome.

\section{Introduction}

During acute myocardial infarction, failure to unblock the infarct-related vessel is associated with poor outcome and prognosis. It is evident from both laboratory and clinical studies that the benefits of thrombolytic therapy are conferred by restoration of patency of the infarct-related artery $(1-3)$. The success of reperfusion therapy is commonly assessed by the normalization of segment $\mathrm{T}$ elevation in the surface electrocardiogram,

the occurrence of reperfusion arrhythmias and the resolution of infarct-related chest pain (4). Predictability of reperfusion proved to be clearly insufficient in several trials using these criteria (5). To date, reliable determination of reperfusion is only possible by coronary angiography. However, acute routine angiography in all patients receiving thrombolytic therapy is impractical or unavailable in an emergency setting and may eventually 
cause harm to some patients. Hence, reliable methods other than angiography are needed to detect coronary reperfusion early during the hospital course. A single non-invasive marker to evaluate reperfusion would be of significant clinical benefit. The ideal application would be the use of a simple serum test as an early non-invasive method to assess successful reperfusion.

For troponin $\mathrm{T}$ it has been suggested in several studies that the effects of reperfusion on the troponin $\mathrm{T}$ plasma time-concentration curves in acute myocardial infarction can be used to non-invasively assess the effectiveness of thrombolytic therapy (6-15). A characteristic biphasic change in plasma concentration has been described, especially in patients with early reperfusion after thrombolytic therapy $(6.16,17)$. Intracellular compartmentation of troponin $T$, i.e. the presence of both free cytosolic and structurally bound troponin $\mathrm{T}$, seems the primary cause of this biphasic troponin T release into plasma (6, $16,18)$. In fresh cardiac tissue the free cytosolic troponin $\mathrm{T}$ fraction is about $4-6 \%$ of the total troponin $\mathrm{T}$ content in cardiac tissue $(6,19)$. The structurally bound troponin $\mathrm{T}$ has to be dissociated from the contractile myofibrillar structures before it can be released into the circulation and is therefore more slowly released into plasma compared to the free cytosolic fraction, resulting in a biphasic time-concentration curve. In the isolated perfused rat heart it was demonstrated that prolonged ischemia induces a continuous liberation of cardiac troponin $\mathrm{T}$, most probably from disintegrating myofibres, whereas membrane damage leads almost exclusively to leakage of the functionally unbound troponin $\mathrm{T}$ pool. These findings may explain the biphasic serum concentration changes of cardiac troponin $\mathrm{T}$ in patients showing reperfusion after acute myocardial infarction (18).

In a recent study, in patients treated with thrombolytic therapy, we found that the total plasma release of troponin T after 72 hours is about $5 \%$ and after 168 hours about $8 \%$ of the total recovery of the cytoplasmic cardiac enzymes creatine kinase and hydroxybutyrate dehydrogenase after 72 hours (19). Cumulative release was expressed in gram equivalents of healthy heart muscle per litre plasma, i.e. infarct size $(20,21)$.

The aim of the present study is to investigate the cumulative release of troponin $\mathrm{T}$ in different patient groups. As troponin $\mathrm{T}$ is bound to myofibrillar structures, presence or absence of reperfusion within 24 hours might influence the total release of this protein in a different way compared to total plasma release of the free cytosolic cardiac markers. Therefore, the timed cumulative troponin $\mathrm{T}$ release pattern has been compared with the cumulative release patterns of the cytoplasmic cardiac enzymes creatine kinase and hydroxybutyrate dehydrogenase in patients treated with thrombolytic therapy, both reperfused and non-reperfused and in patients not receiving thrombolytic therapy.

\section{Patients and Methods}

Patients

Patients (12 men and 11 women) presented at the Department of Cardiology of the Hospital DeWever en Gregorius in Heerlen with chest pain and segment $T$ elevation typical of acute myocardial infarction within 6 hours after the onset of symptoms were included in this study.

From these patients 16 (11 men and 5 women) were treated with thrombolytic therapy. First $160 \mathrm{mg}$ of acetylosalicylic acid (aspirin) were given (unless already given by general practitioner or ambulance nurses), followed by thrombolytic therapy, which consisted of 1.5 million units of streptokinase, given by infusion in $40 \mathrm{~min}$. Four hours after starting thrombolytic therapy heparin was given, 12500 units subcutaneously, every $12 \mathrm{~h}$, for 5 days.

On the basis of clinical symptoms and coronary arteriograms within $24 \mathrm{~h}$, the patients treated with thrombolytic therapy, streptokinase $(S)$, were divided into two groups, reperfused $(n=9$, group $S^{+} R^{+}$) and non-reperfused $\left(n=7\right.$, group $S^{+} R^{-}$) patients. The third group (group $\mathrm{S}^{-}$) consisted of seven patients (6 women and $1 \mathrm{man}$ ) not treated with thrombolytic therapy. In this group no coronary arteriograms were performed and the absence of reperfusion was judged from clinical symptoms only.

All patients included in the study had given informed consent. Excluded were patients with increased risk of bleeding, previous coronary bypass surgery or Q-wave infarction in the same location, severe hepatic or renal disease, or inability to give informed consent.

Venous blood samples of $10 \mathrm{ml}$ were obtained just before starting thrombolytic therapy and $1,2,3,4,5,6,8,10,14,18,22,28,34$, $46,58,70,82,94,118,142,166$ hours later. Exact sampling times were recorded and expressed as time after the onset of symptoms. Most samples were taken from indwelling catheters and care was taken to prevent haemolysis. Contamination with infused solutions was prevented by using a second catheter for infusion purposes. Blood was collected in pre-distributed and labelled tubes, containing dry heparin to prevent clotting and was taken to the laboratory immediately. Plasma samples, obtained after routine centrifugation, were stored at $-70^{\circ} \mathrm{C}$ until analysis. All procedures followed were approved by the Medical Ethical Committee of the Hospital. Patient data for the three groups are presented in table 1 .

\section{Enzyme and troponin $T$ assays}

\section{Creatine kinase and hydroxybutyrate dehydrogenase}

Enzymatic activities of creatine kinase and hydroxybutyrate dehydrogenase were measured spectrophotometrically at $37^{\circ} \mathrm{C}$ using a centrifugal analyzer (Cobas Bio System, Hoffmann La Roche, Basel, Switzerland). Commercially available test kits were used for creatine kinase- $\mathrm{N}$-acetylcysteine (International Federation of Clinical Chemistry [IFCC] recommendation, Unimate 3 Roche, art no. 0736473 ) and hydroxybutyrate dehydrogenase (Deutsche Gesellschaft für Klinische Chemie [DGKC] recommendation, optimized test from Boehringer, art no. 1442 589). The hydroxybutyrate dehydrogenase test is based on preferential catalytic activity of the myocardial isoforms $\mathrm{LDH}_{1}$ and $\mathrm{LDH}_{2}$ of lactate dehydrogenase in the conversion of $\alpha$-ketobutyrate. Activities were expressed in micromoles of substrate converted per minute (U), either per litre of plasma $(\mathrm{U} / \mathrm{l})$ or per gram wet weight of tissue $(\mathrm{U} / \mathrm{g})$.

\section{Troponin $T$}

Troponin $\mathrm{T}$ was measured using the troponin $\mathrm{T}$ immunoassay from Boehringer Mannheim (22). The assay was carried out in coated tubes, using the Boehringer Mannheim ES22 photometer. 
Cumulative release of enzymes and troponin $T$ into plasma

$\mathrm{Q}(t)$, the cumulative release of enzyme activity and troponin $\mathrm{T}$ concentration per litre of plasma from the onset of acute myocardial infarction $(t=0)$ up to time $t$, was calculated with the following expression for a two-compartment model for circulating proteins:

$\mathrm{Q}(t)=\mathrm{C}(t)+\mathrm{TER} \int_{0}^{\mathrm{t}} \exp \{-\operatorname{ERR}(t-\tau)\} \mathrm{C}(\tau) \mathrm{d} \tau+\mathrm{FCR} \int_{0}^{\mathrm{t}} \mathrm{C}(\tau) \mathrm{d} \tau$.

The three terms are the enzyme activity in plasma, the extravasated activity and the activity eliminated from plasma, all three expressed per litre of plasma. The parameters TER, ERR and FCR represent the fractional rate constants for transcapillary escape, extravascular return and fractional catabolism, respectively. This two-compartment model has been validated in the $\operatorname{dog}(21,23,24)$ and parameter values estimated in man are (20):

$$
\begin{aligned}
& \mathrm{FCR}_{\text {HBDH }}=0.015 \mathrm{~h}^{-1}, \mathrm{FCR}_{\mathrm{CK}}=0.20 \mathrm{~h}^{-1}, \\
& \mathrm{TER}=0.014 \mathrm{~h}^{-1} \text { and ERR }=0.018 \mathrm{~h}^{-1} .
\end{aligned}
$$

For troponin $\mathrm{T}$, a value of FCR $=0.11 \pm 0.05 \mathrm{~h}^{-1}$ (mean $\pm \mathrm{SD}$ ) was obtained from a fitting procedure on troponin $\mathrm{T}$ and hydroxybutyrate dehydrogenase plasma curves, as described by Willems et al. $(19,20)$. The procedure is based on simultaneous release of the two proteins from the same (cytoplasmic) compartment, that is, the released troponin $T$ should be the free cytosolic fraction. Therefore fitting was limited to the first 24 hours after first symptoms and it was verified that fitting over 18 or 30 hours gave similar results, which indicates that the release of fibrillar troponin $T$ remains negligible during this period. The mean obtained value of $F C R_{\text {troponin }} \mathrm{T}$ $=0.11 \mathrm{~h}^{-1}$ was used in the calculations (19). The calculations are not influenced by the plasma release rates. Knowledge of the clearance and extravasation rates of proteins once entered into the circulation are sufficient for calculation of the cumulative release into the plasma compartment (25). The two pools used in the two-compartment model are the intra- and extravascular pool and not the free and bound proteins. So with the two-compartment model for circulating proteins, the amount of protein entering the circulation can be calculated. The model has been extensively verified both in animal and in experimental studies $(20,25-27)$.

Plasma enzyme activities measured at time $\mathrm{t}, \mathrm{C}(t)$, were corrected by subtraction of the normal steady state activities $\mathrm{C}_{\mathrm{s}}$. If the first plasma sample was obtained within 4 hours after the onset of symptoms, the corresponding enzyme activities were used for $\mathrm{C}_{s}$. In the remaining cases, fixed mean values of $100 \mathrm{U} / \mathrm{l}, 112 \mathrm{U} / \mathrm{l}$ and $0 \mu \mathrm{g} / 1$ were used for creatine kinase, hydroxybutyrate dehydrogenase and troponin $T$, respectively.

\section{Infarct size in g-eq of tissue per litre of plasma}

In order to express myocardial injury in g-eq of healthy myocardium per litre of plasma, the cumulative release of enzyme per litre of plasma was divided by the respective enzyme content per gram wet weight of cadiac tissue. For creatine kinase $2163 \mathrm{U} / \mathrm{g}$ wet weight, for hydroxybutyrate dehydrogenase $156 \mathrm{U} / \mathrm{g}$ and for troponin $\mathrm{T} 234 \mu \mathrm{g} / \mathrm{g}$ were used $(19,28)$.

\section{Statistical analysis}

The release curves of proteins into plasma are presented as means with standard error of the mean. Pearsons correlation coefficient was calculated to show relations between cumulative enzyme and troponin T release. The Mann Whitney U-test was used for nonparametric comparison of data of two independent groups. The level of significance was set at $p<0.05$.

\section{Results}

Mean plasma concentration after acute myocardial infarction

Mean plasma troponin $\mathrm{T}$ concentrations and creatine kinase and hydroxybutyrate dehydrogenase activities as a function of time after the onset of symptoms in the three patient groups are shown respectively in the figures 1a,b,c. At the right side of each figure an enlargement of the plasma release curves during the first 10 hours is given. Differences in time from onset of symptoms to peak are most significant between patients treated with thrombolytic therapy without reperfusion (group $\mathrm{S}^{+} \mathrm{R}^{-}$) compared to patients not treated with thrombolytic therapy, showing no reperfusion $\left(\mathrm{S}^{-}\right)$, see table 1 .

The biphasic troponin $\mathrm{T}$ curve clearly indicates a second source of release, starting about 40 hours after the onset of symptoms. The biphasic troponin $\mathrm{T}$ release is more clear in patients treated with thrombolytic therapy compared to patients not treated with thrombolytic therapy. In patients not treated with thrombolytic therapy, showing no reperfusion, delayed time to peak values were found for all cardiac markers studied and for troponin $\mathrm{T}$ the ratio of plasma troponin $\mathrm{T}$ at $16 \mathrm{~h}$ to $36 \mathrm{~h}$ was significantly lower in the non-treated non-reperfused patients (tab. 1).

\section{Cumulative release of enzymes into plasma}

For troponin $\mathrm{T}$, creatine kinase and hydroxybutyrate dehydrogenase, the time versus cumulative release, expressed in gramequivalents of tissue per litre of plasma, is shown respectively in the figures $2 a, b$ and $c$. At the right side of each figure an enlargement of the cumulative release during the first 10 hours is given. Figure 2 and table 1 show that the cumulatively released quantities of creatine kinase and hydroxybutyrate dehydrogenase amount to approximately similar estimates of the extent of injury, i. e., infarct size after 72 to 100 hours. Cumulative troponin $\mathrm{T}$ release is still increasing after 168 hours and is only a fraction of cumulative enzyme release.

\section{Cumulative release of troponin $\mathrm{T}$ into plasma}

After 168 hours the mean troponin $T$ release, expressed as a percentage of the cumulative enzyme release, is comparable between the groups and is only 6.6 to $8.7 \%$ of the cumulative enzyme release after 72 hours (tab. 1). Figure 2a shows that troponin $T$ release still continues after 168 hours, whereas the release of creatine kinase and hydroxybutyrate dehydrogenase is already completed after 72-100 hours.

\section{Correlation between infarct size calculated with different cardiac markers}

Figure 3 shows that although the mean total release of troponin $\mathrm{T}$ after 72 hours is only a fraction of the mean total release observed for hydroxybutyrate dehydrogenase after 72 hours, a highly significant correlation is observed between cumulative hydroxybutyrate dehydro- 
genase release and cumulative troponin $T$ after 168 hours for all three groups. Slope and intercept of the regression lines are comparable, indicating that the total cumulative release of troponin $\mathrm{T}$ is not influenced by treatment strategy or outcome.

Figure 3 shows that the percentage troponin $\mathrm{T}$ released is not influenced by infarct size.

\section{Discussion}

\section{Patient groups}

Since the introduction of thrombolysis this therapy has proven to be very effective in patients suffering from acute myocardial infarction. For that reason every patient with signs of acute myocardial infarction will be stratified for thrombolysis, unless there is a significant contraindication. Mostly these contraindications are: time passed since the onset of symptoms (i.e. $>6-9$ hours), a history of recent cerebrovascular accident or a history of gastro-intestinal bleeding or ulcer. It goes without saying that these factors influence the composition of the two different groups, so that it is very difficult to include a group of patients receiving no thrombolytic therapy that matches the other group. In the present study treatment delay was comparable between the groups.

As we primarily investigated differences in cumulative release between the groups, clinical symptoms and coronary arteriograms within 24 hours were sufficient to determine vessel patency. Patients with completely different vessel patency were present and therefore a possible influence of vessel patency on the cumulative release of troponin $T$ could be investigated by comparing cumulative enzyme and cumulative troponin $T$ release; especially since it is known that cumulative enzyme release, i.e. enzymatic infarct size, is not influenced by vessel patency (29). Van der Laarse showed that the relation between enzymatic infarct size assessed from cumulative hydroxybutyrate dehydrogenase release and left ventricular performance was not influenced by the presence or absence of reperfusion (29). a

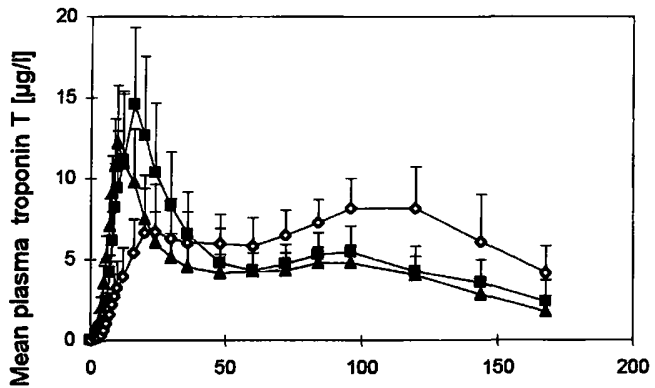

b

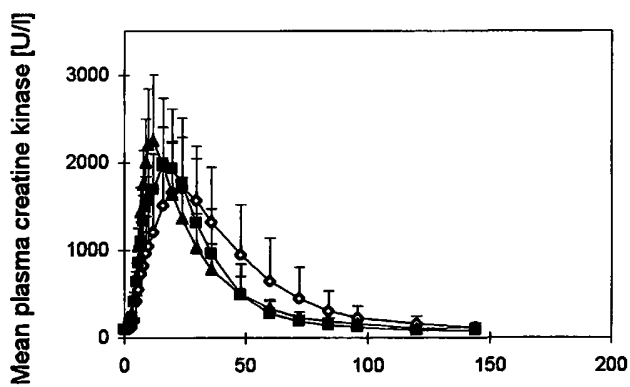

c

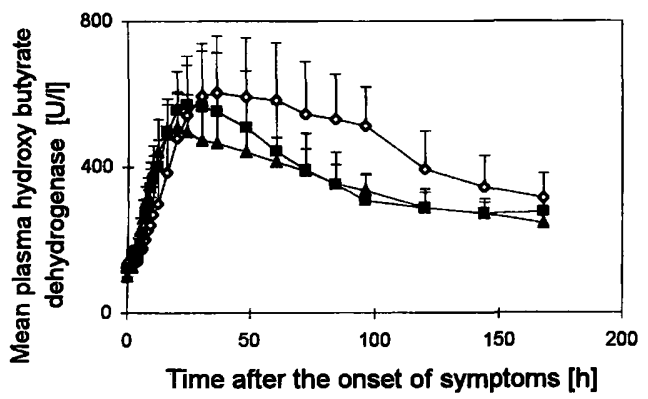

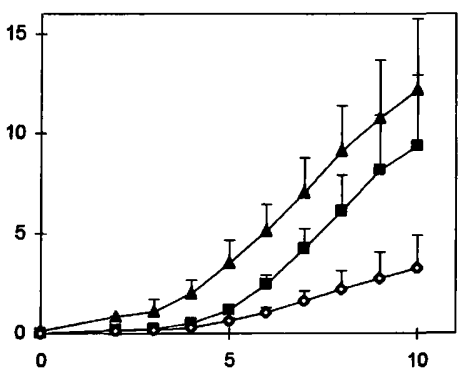
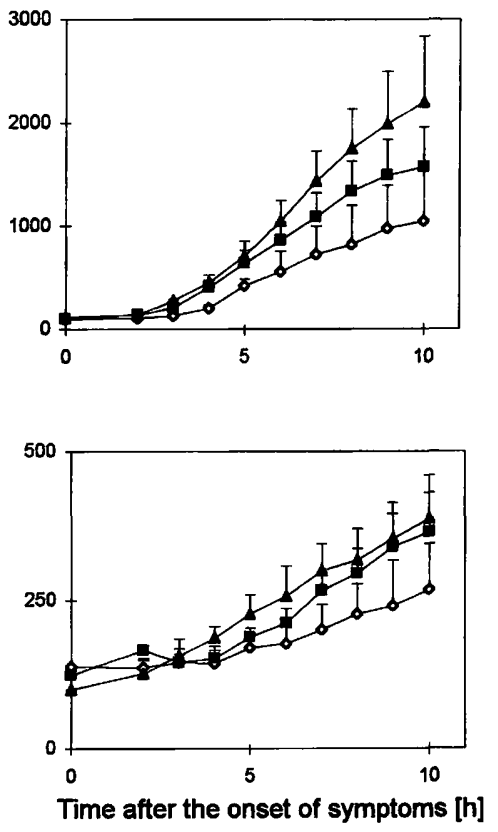

Fig. 1a-c Mean plasma concentrations of troponin $T \times 100$ in micrograms per litre (a) and of creatine kinase (b) and hydroxybutyrate dehydrogenase (c) expressed in $\mathrm{U} / \mathrm{l}$, in patients treated with thrombolytic therapy, with reperfusion $\left(\Lambda, S^{+} R^{+}, n=9\right)$ or with- out reperfusion $\left(\boldsymbol{E}, \mathrm{S}^{+} \mathrm{R}^{-}, \mathrm{n}=7\right)$ and in patients not treated with thrombolytic therapy and showing no reperfusion $\left(\diamond, S^{-}, n=7\right)$. Upper standard error of the mean is indicated. 
Tab. 1 Patient data

\begin{tabular}{|c|c|c|c|c|c|c|}
\hline Patient group & $\begin{array}{l}S^{+} R^{+} \\
(n=9) \\
\text { Mean } \pm S D\end{array}$ & $\begin{array}{l}\mathrm{S}^{+} \mathrm{R}^{-} \\
(\mathrm{n}=7) \\
\text { Mean } \pm \mathrm{SD}\end{array}$ & $\begin{array}{l}S^{-} \\
(n=7) \\
\text { Mean } \pm S D\end{array}$ & $\begin{array}{l}\mathrm{S}^{+} \mathrm{R}^{+} \\
\text {vs } \mathrm{S}^{-}\end{array}$ & $\begin{array}{l}S^{+} R^{-} \\
\text {vs } S^{-}\end{array}$ & $\begin{array}{l}\mathrm{S}^{+} \mathrm{R}^{+} \\
\text {vs } \mathrm{S}^{+} \mathbf{R}^{-}\end{array}$ \\
\hline Treatment delay $[\mathrm{h}]$ & $2.23 \pm 1.32$ & $2.28 \pm 1.41$ & $2.21 \pm 1.09$ & ns & ns & ns \\
\hline Age [years] & $61.4 \pm 11.3$ & $58.1 \pm 6.7$ & $72.7 \pm 8.6$ & ns & 0.015 & ns \\
\hline Time peak CK $[\mathrm{h}]$ & $12.0 \pm 3.4$ & $15.3 \pm 5.9$ & $19.7 \pm 6.5$ & 0.019 & ns & ns \\
\hline Time peak HBDH $[\mathrm{h}]$ & $21.3 \pm 6.0$ & $22.3 \pm 5.5$ & $44.3 \pm 23.5$ & 0.014 & 0.022 & ns \\
\hline Time peak troponin $\mathrm{T}[\mathrm{h}]$ & $12.9 \pm 3.8$ & $20.0 \pm 8.6$ & $24.0 \pm 10.1$ & 0.020 & ns & 0.05 \\
\hline Troponin $\mathrm{T}$ at $16 \mathrm{~h} /$ troponin $\mathrm{T}$ at $36 \mathrm{~h}$ & $2.04 \pm 0.85$ & $2.02 \pm 0.91$ & $0.94 \pm 0.65$ & 0.016 & ns & ns \\
\hline $\mathrm{Q}_{\text {HBDH }}(72)$ [g-eq/1] & $5.23 \pm 2.89$ & $5.28 \pm 4.67$ & $6.44 \pm 4.97$ & ns & ns & ns \\
\hline $\mathrm{Q}_{\mathrm{cK}}(72)[\mathrm{g}-\mathrm{eq} / \mathrm{l}]$ & $5.32 \pm 4.90$ & $5.49 \pm 5.02$ & $6.52 \pm 6.50$ & ns & ns & ns \\
\hline$Q_{\text {troponin T }}(72)[g-e q / 1]$ & $0.21 \pm 0.16$ & $0.26 \pm 0.21$ & $0.22 \pm 0.16$ & ns & ns & ns \\
\hline $\mathrm{Q}_{\text {troponin T }}(168)[\mathrm{g}-\mathrm{eq} / \mathrm{l}]$ & $0.36 \pm 0.27$ & $0.44 \pm 0.36$ & $0.50 \pm 0.38$ & ns & ns & ns \\
\hline$Q_{\text {troponin T }}(168) / Q_{\text {HBDH }}(72) \times 100[\%]$ & $6.6 \pm 3.3$ & $8.7 \pm 2.9$ & $8.6 \pm 2.4$ & ns & ns & ns \\
\hline $\mathrm{Q}_{\text {troponin T }}(168) / \mathrm{Q}_{\mathrm{HBDH}}(168) \times 100[\%]$ & $6.1 \pm 2.9$ & $8.3 \pm 3.0$ & $7.8 \pm 2.4$ & ns & ns & ns \\
\hline $\mathrm{Q}_{\text {HBDH }}(24) / \mathrm{Q}_{\text {HBDH }}(72) \times 100[\%]$ & $66.7 \pm 16.9$ & $72.7 \pm 15.7$ & $55.7 \pm 21.2$ & ns & ns & ns \\
\hline $\mathrm{Q}_{\text {HBDH }}(10) / \mathrm{Q}_{\text {HBDH }}(72) \times 100[\%]$ & $35.7 \pm 16.8$ & $34.5 \pm 20.4$ & $13.2 \pm 12.3$ & 0.018 & ns & ns \\
\hline $\mathrm{Q}_{\mathrm{CK}}(10) / \mathrm{Q}_{\mathrm{CK}}(72) \times 100[\%]$ & $30.4 \pm 14.3$ & $28.5 \pm 16.1$ & $19.7 \pm 32.2$ & 0.052 & ns & ns \\
\hline $\mathrm{Q}_{\text {troponin T }}(10) / \mathrm{Q}_{\text {troponin T }}(168) \times 100[\%]$ & $22.2 \pm 18.5$ & $12.7 \pm 10.7$ & $5.4 \pm 6.1$ & 0.008 & ns & ns \\
\hline $\mathrm{Q}_{\text {troponin T }}(5) / \mathrm{Q}_{\text {troponin T }}(168) \times 100[\%]$ & $14.9 \pm 25.9$ & $3.0 \pm 3.2$ & $3.2 \pm 5.6$ & ns & ns & ns \\
\hline
\end{tabular}

$\mathrm{S}^{+} \mathrm{R}^{+}=$streptokinase treatment, reperfusion

$\mathrm{S}^{+} \mathrm{R}^{-}=$streptokinase treatment, no reperfusion

$\mathrm{CK} \quad=$ creatine kinase

$\mathrm{S}^{-}=$no streptokinase treatment
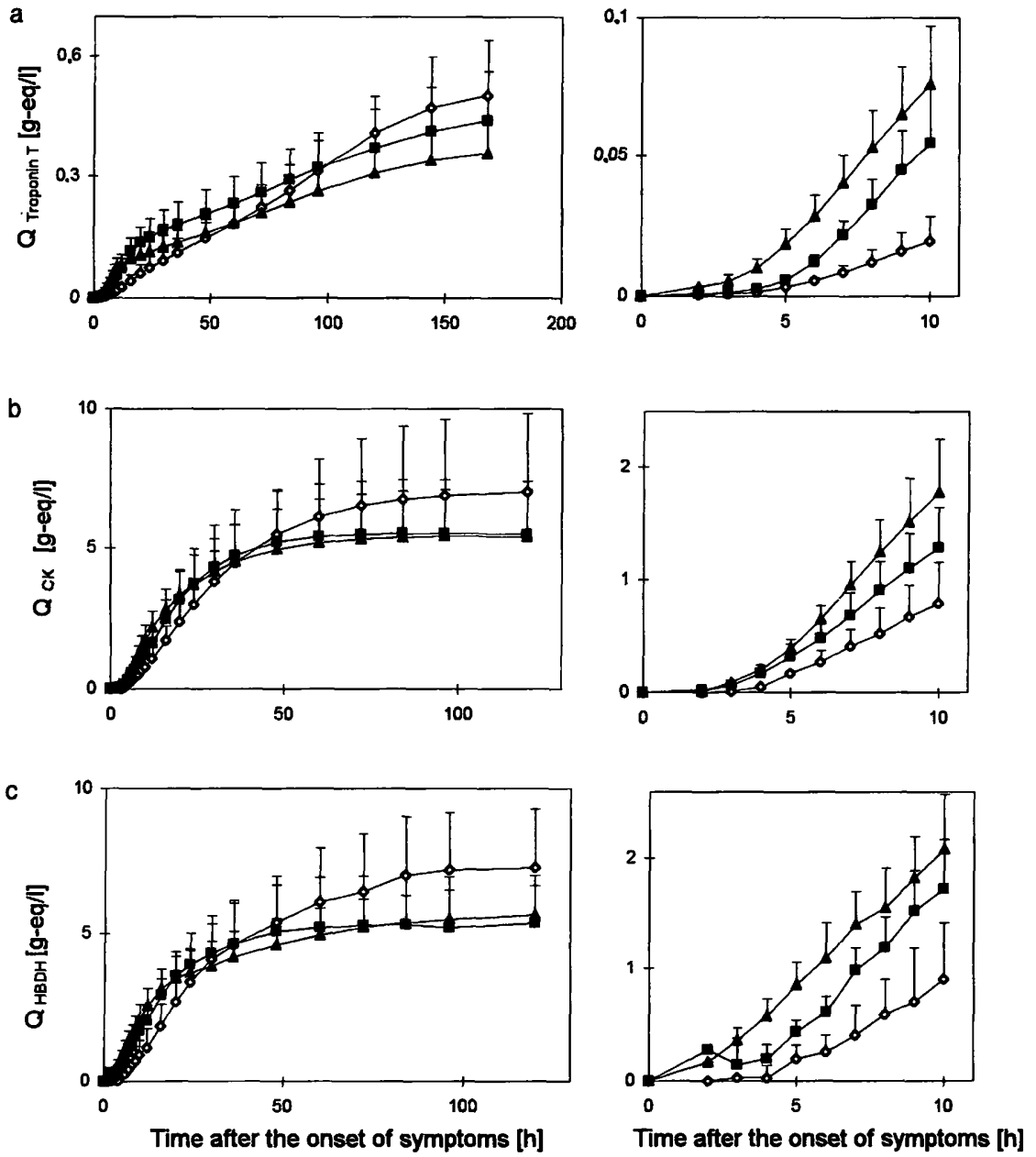

Fig. 2a-c Mean cumulative release of troponin $T$ (a), creatine kinase (b) and hydrosybutyrate dehydrogenase (c) expressed in $\mathrm{g}$-eq/1 in patients treated with thrombolytic therapy, with reperfu- sion $\left(\Delta, S^{+} R^{+}, n=9\right)$ or without reperfusion $\left(\square, S^{+} R^{-}, n=7\right)$ and in patients not treated with thrombolytic therapy $\left(\diamond, S^{-}\right.$, $\mathbf{n}=7$ ). Upper standard error of the mean is indicated. 
Of course in studies on early prediction of vessel patency, 90 minutes angiography should be preferred to judge the presence or absence of early reperfusion.

\section{Troponin $\mathrm{T}$ and prediction of reperfusion}

Clinical assessment of reperfusion following thrombolytic therapy is an important feature for a clinician. As
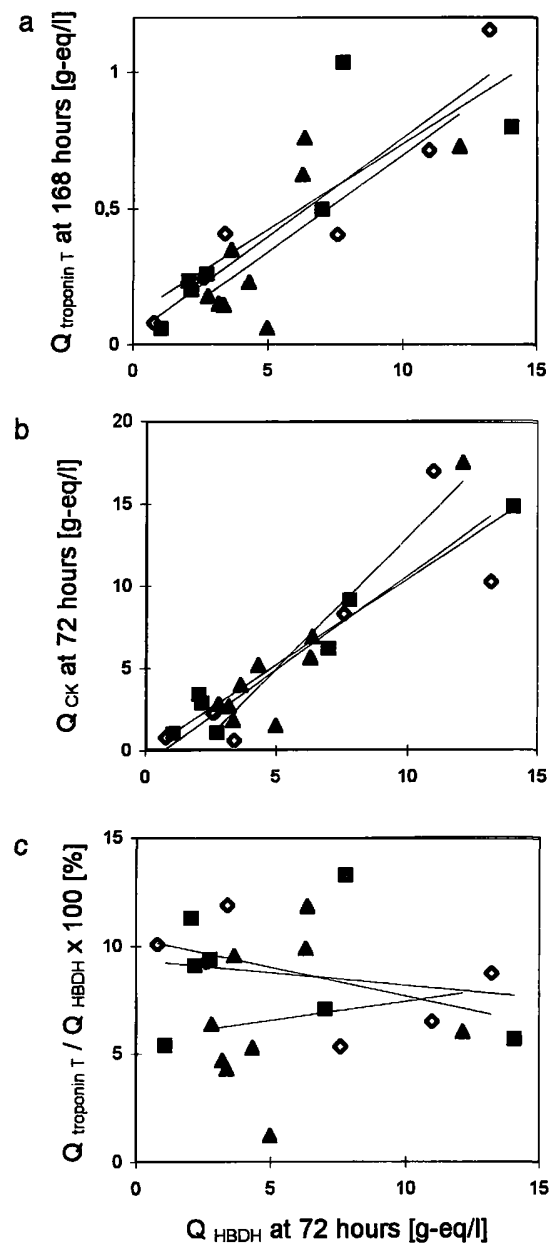

Fig. 3a-c Correlation between cumulative hydroxybutyrate dehydrogenase release at 72 hours and cumulative troponin $T$ release at 168 hours (a) and between hydroxybutyrate dehydrogenase and cumulative creatine kinase release at 72 hours (b), expressed in gram equivalents cardiac tissue per litre plasma in patients treated with thrombolytic therapy, with reperfusion $\left(\Delta, S^{+} R^{+}, n=9\right)$ or without reperfusion $\left(\mathbf{n}, \mathrm{S}^{+} \mathrm{R}^{-}, \mathrm{n}=7\right)$ and in patients not treated with thrombolytic therapy showing no reperfusion $\left(\diamond, S^{-}, n=7\right)$. Fig. 3c presents the relation between $\left(\mathrm{Q}_{\text {troponin } T}(168) / \mathrm{Q}_{\mathrm{HBDH}}(72)\right)$ $\times 100$ and the cumulative hydroxybutyrate dehydrogenase release at 72 hours for the different groups.

Regression lines:

fig. 3a:

$\Delta \mathrm{r}=0.92 ; \mathrm{y}=0.071 \mathrm{x}-0.013$

$\mathrm{r}=0.95 ; \mathrm{y}=0.063 \mathrm{x}+0.109$

$\diamond \mathrm{r}=0.96 ; \mathrm{y}=0.072 \mathrm{x}+0.036$

fig. 3b:

$\Delta \mathrm{r}=0.93 ; \mathrm{y}=1.60 \mathrm{x}-3.05$

$\mathrm{r}=0.90 ; \mathrm{y}=1.05 \mathrm{x}-0.05$

$\diamond \mathrm{r}=0.86 ; \mathrm{y}=1.14 \mathrm{x}-0.81$

fig. 3c:

$\Delta \mathrm{r}=0.15 ; \mathrm{y}=0.177 \mathrm{x}+5.6$

$\mathrm{r}=0.19 ; \mathrm{y}=0.121 \mathrm{x}+9.4$

$\diamond \mathrm{r}=0.32 ; \mathrm{y}=-0.273 \mathrm{x}+10.4$ a gold standard coronary angiography, performed ninety minutes after the start of thrombolytic therapy, offers a clear view of the status of the infarct-related vessel, but is expensive, and may cause harm to the patient (5). Clinical assessment of reperfusion on ECG-changes and ventricular arrhythmias alone, however, is related with a lower prognostic value, so the use of acute biochemical markers is essential and has been the subject of many investigations $(7,30)$. Troponin $\mathrm{T}$ has also been suggested as a biochemical marker of reperfusion $(6,8,12$, 14). Katus et al. first showed the characteristic biphasic plasma time-concentration curve for troponin $\mathrm{T}$ and indicated that all patients with reperfusion $<5.5 \mathrm{~h}$ after the onset of acute myocardial infarction had a ratio of peak troponin $T$ on day 1 , to day 4 of $>1.0$. The ratio was $<1.0$ in non-reperfused patients and in those with reperfusion after $5.5 \mathrm{~h}(6)$.

Burlina et al. found $94 \%$ efficiency using the ratio of serum troponin $\mathrm{T}$ at $16 \mathrm{~h}$ to serum troponin $\mathrm{T}$ at $32 \mathrm{~h}$ after onset of chest pain. However, in this study most of the non-reperfused patients were not treated with thrombolytic therapy and reperfusion was detected from clinical symptoms and was confirmed angiographically only in some cases (31).

Rempis et al. demonstrated that the probability of reperfusion was $>95 \%$ when the ratio of troponin $\mathrm{T}$ concentration at $14 \mathrm{~h}$ over $38 \mathrm{~h}$ exceeded 1.09 . They showed a much better discriminating value of this ratio in patients with reperfusion occurring within 4 hours after start of treatment (12). We could confirm their results in nonreperfused non-treated patients compared to reperfused treated patients. In patients treated with thrombolytic therapy, assessment of reperfusion from the troponin $\mathrm{T}$ $(16 / 36)$ ratio was not possible. This might be caused by the fact that we determined vessel patency within 24 hours and not within 90 minutes. So, in our patients reperfusion did not necessarily occur within 4 hours after start of treatment. This does not interfere with our goal to compare the total amount of troponin $T$ released in the different patient groups.

For reliable prediction of thrombolysis from initial slopes of cardiac markers, samples should be taken every 15 minutes after start of treatment to estimate the initial slope $(8,10,14)$. Using early initial slopes of serum markers to predict reperfusion Zabel et al. found the best discriminating results using myoglobin. Compared to troponin $\mathrm{T}$ or creatine kinase-MB mass initial slopes, myoglobin showed earlier rise, yielding a better negative predictive value and a higher area under the ROC curve for non-invasive prediction of coronary artery patency after thrombolytic therapy (8). Abe et al. found a comparable accuracy of $92 \%$ to predict reperfusion from initial slope measurements for creatine kinaseMB mass and troponin T. Initial slopes were obtained 
from 15 minutes samples during the first 90 minutes (10). Laperche et al. showed that reliable early non-invasive diagnosis of patency after thrombolysis from plasma myoglobin or tropanin $\mathrm{T}$ is only possible in patients treated $>3$ hours after onset of symptoms by use of criteria derived from the relative increase over 90 minutes (14).

The aim of the present study was not to predict reperfusion from plasma time activity or concentration curves, but to investigate the cumulative release of troponin $T$, as a percentage of cumulative cytosolic enzyme release, in different patient groups. As troponin $\mathrm{T}$ is bound to myofibrillar structures, presence or absence of reperfusion might influence the cumulative release of this protein in a different way compared to the free cytosolic enzymes; especially because it is known that cumulative enzyme release, i. e. enzymatic infarct size, is not influenced by vessel patency (29). Van der Laarse et al. showed that the relation between enzymatic infarct size assessed from cumulative hydroxybutyrate dehydrogenase release and left ventricular performance was not influenced by the presence or absence of reperfusion (29). As we studied cumulative release, plasma timeconcentration curves and cumulative release patterns were indicated and calculated from the onset of symptoms and not from the onset of treatment. The latter is only to be preferred in studies on prediction of reperfusion from initial slopes.

Only few studies are available on the influence of reperfusion or treatment of thrombolytic therapy on cumulative enzyme release, i. e., infarct size or release rate. In a large scale study Van der Laarse et al. found that thrombolysis in the early phase of acute myocardial infarction limits infarct size and that intra-coronary streptokinase treatment itself positively influences the enzyme release rate, from the infarcted myocardium, independent of treatment outcome determined angiographically (29). In the present study a comparable trend is shown, although not significant. A larger study is necessary to confirm these findings.

\section{Recovery of the different markers}

Quantitative recovery of cytosolic cardiac proteins into plasma after ischaemic myocardial damage has been demonstrated in experimental studies. The total activities of free cytosolic creatine kinase and hydroxybutyrate dehydrogenase lost from dog heart after permanent coronary occlusion (21) equalled the total release of these proteins into plasma. These results cannot be directly extrapolated to man. It was shown in the dog that protein preparations infused into the infarcted myocardium reach the circulation within a few hours (27). Such a rapid washout of protein is effected by direct extravasation and flushing of the micro-vessels by the residual blood flow in the infarcted area. In man, conditions could be different and the washout period may be longer. However, the fact that similar estimates of infarct size are obtained for enzymes indicate that, also in man, these cytoplasmic proteins are recovered completely in plasma within $72-100$ hours after the onset of symptoms $(32,33)$.

In a recent study we found that in patients receiving thrombolytic therapy, cumulative troponin $T$ release is only a fraction of cumulative cytoplasmic creatine kinase or hydroxybutyrate dehydrogenase release (19). Using a total cardiac troponin $\mathrm{T}$ content of $234 \mu \mathrm{g} / \mathrm{g}$ wet weight the mean cumulative troponin $\mathrm{T}$ release after 168 hours is about $8 \%$ of the cumulative release of cytoplasmic enzymes after 72 hours, when expressed in gram equivalents normal cardiac tissue. So, for proteins bound to myofibrillar structures there is no rapid washout, and only the free circulating troponin $T$ and the troponin $T$ released from the myofibrils after ischaemia reaches the circulation. This is only a small fraction of the total amount of troponin T present in cardiac tissue (19).

From the present study it became clear that cumulative troponin T release is independent of treatment strategy or outcome. Figure 3a shows that the correlation and slope of cumulative hydroxybutyrate dehydrogenase versus troponin $T$ release is not influenced by treatment strategy or outcome. Moreover, the percentage of troponin $\mathrm{T}$ released is not influenced by infarct size (fig. 3c).

\section{Troponin $\mathrm{T}$ for estimation of infarct size}

Estimation of the extent of ischaemic myocardial injury from the release of cytoplasmic cardiac enzymes into plasma has become normal clinical practice and has been applied successfully in the evaluation of the effect of thrombolytic therapy after acute myocardial infarction $(34,32,35)$. Several clinical studies have produced convincing correlations between enzymatic and histologic estimates of infarct size $(26,27,36-39)$ or between enzymatic infarct size and infarct size estimated from photon-emission computed tomography (40) or radionuclide estimates of myocardial infarct size (41).

We showed that although cumulative troponin $\mathrm{T}$ release is only a fraction of the cumulative enzyme release, there is a good correlation between cumulative cytoplasmic enzyme release (infarct size) and cumulative troponin $\mathrm{T}$ release, independent of treatment strategy or treatment outcome, vessel patency (fig. 3a-b).

\section{Conclusions}

- Creatine kinase and hydroxybutyrate dehydrogenase release was completed within $72-100$ hours in all patients, whereas troponin $\mathrm{T}$ release was still increasing after 168 hours. 
- There was a significant difference in time to peak value for cardiac enzymes and troponin $T$ in patients treated with thrombolytic therapy, showing reperfusion, compared to those not treated with thrombolytic therapy showing no reperfusion.

- Although plasma time-concentration curves of troponin $T$ in patients treated with thrombolytic therapy showing reperfusion, differed significantly from data of patients not treated with thrombolytic therapy and showing no reperfusion, after 168 hours the cumulative troponin $\mathrm{T}$ release was only $6-8 \%$ of the cardiac enzyme release for all patients and is therefore not influenced by the treatment strategy.

- Although cumulative troponin $\mathrm{T}$ release is only a fraction of the cumulative enzyme release, there is a

\section{References}

1. Kennedy J, Ritchie J, Davis K, Stadius M, Maynard C, Fritz $J$. The Western Washington randomized trial of intracoronary streptokinase in acute myocardial infarction. New Engl $\mathbf{J}$ Med $1985 ; 312: 1073-8$.

2. GISSI-1. (Gruppo Italiano per lo studio della streptochinasi nell'infarto miocardico) Effectiveness of intravenous thrombolytic treatment in acute myocardial infarction. Lancet 1986; i:349-60.

3. Tiefenbrunn A, Sobel B. Thrombolysis and myocardial infarction. Fibrinolysis $1991 ; 5: 1-15$.

4. Kircher B, Topol B, O'Neill W, Pitt B. Prediction of infarct coronary artery recanalization after intravenous thrombolytic therapy. Am J Coll Cardiol 1987; 59:513-5.

5. Califf RM, O'Neill W, Stack RS, Aronson L, Mark DB, Mantell $\mathrm{S}$, et al. Failure of simple clinical measurements to predict perfusion status after intravenous thrombolysis. Ann Intern Med 1988; 108:658-62.

6. Katus H, Remppis A, Scheffold T, Diederich K, Kuebler W. Intracellular compartmentation of cardiac troponin $T$ and its release kinetics in patients with reperfused and nonreperfused myocardial infarction. Am J Cardiol 1991; 67:1360-7.

7. Apple FS. Acute myocardial infarction and coronary reperfusion. Serum cardiac markers for the 1990s. Am J Clin Pathol 1992; 97:217-26.

8. Zabel M, Hohnloser SH, Koster W, Prinz M, Kasper W, Just H. Analysis of creatine kinase, CK-MB, myoglobin, and troponin $\mathrm{T}$ time-activity curves for early assessment of coronary artery reperfusion after intravenous thrombolysis. Circulation 1993; 87:1542-50.

9. Mair J, Puschendorf B, Michel G. Clinical significance of cardiac contractile proteins for the diagnosis of myocardial injury. Adv Clin Chem 1994; 31:63-98.

10. Abe S, Arima S, Yamashita T, Miyata M, Okino H, Toda H, et al. Early assessment of reperfusion therapy using cardiac troponin T. J Am Coll Cardiol 1994; 23:1382-9.

11. Mair J, Wagner I, Jacob G, Lechleitner P, Dienstl F, Puschendorf B, et al. Different time courses of cardiac contractile proteins after acute myocardial infarction. Clin Chim Acta 1994; 231:47-60.

12. Remppis A, Scheffold T, Karrer O, Zehelein J, Hamm C, Grunig E, et al. Assessment of reperfusion of the infarct zone after acute myocardial infarction by serial cardiac troponin $\mathrm{T}$ measurements in serum. Br Heart $\mathrm{J}$ 1994; 71:242-8.

13. Lavin F, Kane M, Forde A, Gannon F, Daly K. Comparison of five cardiac markers in the detection of reperfusion after thrombolysis in acute myocardial infarction. Br Heart J 1995; 73:422-7. good correlation between cumulative cytoplasmic enzyme release (infarct size) and cumulative troponin $T$ release, independent of treatment strategy or treatment outcome, vessel patency.

- The rate of enzyme and troponin $T$ release in patients treated with streptokinase seems higher than the release rate in patients not treated with streptokinase and without spontaneous reperfusion. This could mean a direct effect of the thrombolytic agent on the release rate of troponin T. A more extensive study is necessary to confirm this finding.

\section{Acknowledgements}

We thank M. Koenders-Delnoy and $M$. van der Vloet-Boermans, Department of Clinical Chemistry of the Hospital De Wever en Gragorius in Heerlen for their perfect technical assitance.
14. Laperche T, Steg PG, Dehoux M, Benessiano J, Grollier G, Aliot E, et al. A study of biochemical markers of reperfusion early after thrombolysis for acute myocardial infarction. The PERM Study Group. Prospective Evaluation of Reperfusion Markers. Circulation 1995; 92:2079-86.

15. Apple FS, Voss E, Lund L, Preese L, Berger CR, Henry TD. Cardiac troponin, CK-MB and myoglobin for the early detection of acute myocardial infarction and monitoring of reperfusion following thrombolytic therapy. Clin Chim Acta 1995; 237:59-66.

16. Mair J, Artner-Dworzak E, Lechleitner P, Schmidt J, Wagner $\mathrm{I}$, Dienstl $\mathrm{F}$, et al. Cardiac troponin $\mathrm{T}$ in diagnosis of acute myocardial infarction. Clin Chem 1991; 37:845-52.

17. Gerhardt W, Katus H, Ravkilde J, Hamm C, Jorgensen P, Peheim E, et al. Serum troponin $\mathrm{T}$ in suspected ischemic myocardial injury compared with mass and catalytic concentration of serum creatine kinase isoenzyme MB. Clin Chem 1991; 37:1405-11.

18. Remppis A, Scheffold T, Greten J, Haass M, Greten T, Kubler W, et al. Intracellular eompartmentation of troponin T: release kinetics after global ischemia and calcium paradox in the isolated perfused rat heart. J Mol Cell Cardiol 1995; 27:793-803.

19. Kragten J, Hermens W, Van Dieijen-Visser M. Cardiac troponin $\mathrm{T}$ release into plasma after acute myocardial infarction: only fractional recovery compared with enzymes. Ann Clin Biochem 1996; 33:314-23.

20. Willems G, Visser M, Krill M, Hermens W. Quantitative analysis of plasma enzyme levels based on simultaneous determination of different enzymes. Cardiovasc Res 1982; 16:120-31.

21. Hermens W, Van der Veen F, Willems G, Mullers-Bouman M, Schrijvers-van Schendel A, Reneman R. Complete recovery in plasma of enzymes lost from the heart after permanent coronary occlusion in the dog. Circulation 1990; 81:649-59.

22. Katus H, Remppis A, Looser S, Hallermeier K, Scheffold T, Kubler W. Enzyme linked immuno assay of cardiac troponin $\mathrm{T}$ for the detection of acute myocardial infarction in patients. J Mol Cell Cardiol 1989; 21:1349-53.

23. Visser M, Krill M, Willems G, Hermens W. Selection of a suitable model for the plasma clearance and distribution of cardiac enzymes in the dog. Cardiovasc Res 1981; 15:35-42.

24. Van Kreel B, Van der Veen F, Willems G, Hermens W. Circulatory models in assessment of cardiac enzyme release in dogs. Am J Physiol 1993; (Heart Circ Vol 33):H747-H54.

25. Hermens W, Willems G, Visser M. quantification of circulating proteins. The Hague: Martinus Nijhoff Publishers, 1982. 
26. Roberts R. Enzymatic estimation of infarct size. Thrombolysis induced its demise: will it now rekindle its renaissance? Circulation 1990; 81:707-10.

27. Van der Veen F, Hermens W, Willems G, Schrijvers-van Schendel A, Mullers-Boumans M, Reneman R. Time course of cellular enzyme release in dog heart injury. Circ Res 1990; 67:1257-66.

28. Kragten J, Van Nieuwenhoven F, Van Dieijen-Visser M, Theunissen P, Hermens W, Glatz J. Distribution of myoglobin and fatty acid binding protein in human cardiac autopsies. Clin Chem 1996; 42:337-8.

29. Van der Laarse A, Kerkhof PLM, Serruys PW, Hermens WT, Verheugt FWA, Bar FW, et al. Relation between infarct size and left ventricular performance assessed in patients with first acute myocardial infarction randomized to intracoronary or to conventional therapy. Am J Cardiol 1988; 61:1-7.

30. Bahayana V, Henderson AR. Biochemical markers of myocardial damage. Clin Biochem 1995; 28:1- 19.

31. Burlina A, Zaninotto M, Secchiero S, Rubin D, Accorsi F. Troponin $\mathrm{T}$ as a marker of ischemic myocardial injury. Clin Biochem 1994; 27:113-21.

32. Simoons M, Serruys $P$, van den Brand $M$, Res J, Verheugt $F$, Krauss $\mathrm{X}$, et al. Early thrombolysis in acute myocardial infarction: limitation of infarct size and improved survival. $\mathbf{J}$ Am Coll Cardiol 1986; 7:717-28.

33. De Zwaan C, Willems G, Vermeer F, Res J, Verheugt f, Van der Laarse A, et al. Enzyme tests in the evaluation of thrombolysis in acute myocardial infarction. $\mathrm{Br}$ Heart $\mathrm{J}$ 1988; 59:175-83.

34. Anderson JL, Marshall HW, Askins JC, Lutz JR, Sorensen SG. A randomized trial of intravenous and intracoronary streptokinase in patients with acute myocardial infarction. Circulation 1984; 70:606-18.

35. Van de Werf F, Arnold A. For the European Cooperative Study Group for recombinant tissue type plasminogen activator: in- travenous tissue plasminogen activator and size of infarct, left ventricular function and survival in acute myocardial infarction. Br Med J 1988; 297:1374-9.

36. Clark G, Robinson A, Gnepp D, Roberts R, Sobel B. Effects of lymphatic transport of enzyme on plasma creatine kinase time-activity curves after myocardial infarction in dogs. Circ Res 1978; 43:162-9.

37. Bleifeld W, Mathey D, Hanrath P, Buss H, Effert S. Infarct size estimated from serial creatine phosphokinase in relation to left ventricular dynamics. Circulation 1977; 55:303-11.

38. Grande P, Hansen B, Christiansen C, Naestoft J. Estimation of acute myocardial infarct size in men by serum CK-MB measurements. Circulation 1982; 65:756-64.

39. Hackel D, Reimer K, Ideker R, Mikat E, Hartwell T, Parker $C$, et al. Comparison of enzymatic and anatomic estimates of myocardial infarct size in man. Circulation 1984; 70:824-35.

40. Jansen DE, Corbett JR, Wolfe CL, Lewis SE, Gabliani G, Filipchuk N, et al. Quantification of myocardial infarction: a comparison of single photon-emission computed tomography with pyrophosphate to serial plasma MB-creatine kinase measurements. Circulation 1985; 72:327-33.

41. Morrison J, Coromilas J, Munsey D, Robbins M, Zema M, Chiaramida $\mathrm{S}$, et al. Correlation of radionuclide estimates of myocardial infarction size and release of creatine kinase-MB in man. Circulation 1980; 62:277-87.

\section{Received January 22/April 14, 1997}

Corresponding author: Prof. dr. M. P. van Dieijen-Visser, Department of Clinical Chemistry, Academic Hospital Maastricht, P. O. Box 5800, NL-6202 AZ Maastricht, The Netherlands Fax: +31433874692 
